East African Medical Journal Vol. 86 No. 8 August 2009

THE CONTRIBUTION OF VERY LOW BIRTH WEIGHT DEATHS TO INFANT MORTALITY

F. N. Were, MBChB, MMed, FNC, MD, Associate Professor of Newborn Medicine and N. O. Bwibo, MBChB, FAAP, Professor of Paediatrics, Department of Paediatrics and Child Health, College of Health Sciences, University of Nairobi, P.O. Box 19676-00200, Nairobi, Kenya

Request for reprints to: Prof. F. N. Were, Department of Paediatrics and Child Health, College of Health Sciences, University of Nairobi, P. O. Box 20956-00202, Nairobi, Kenya

\title{
THE CONTRIBUTION OF VERY LOW BIRTH WEIGHT DEATHS TO INFANT MORTALITY
}

\author{
F. N. WERE and N. O. BWIBO
}

\begin{abstract}
Background: Infant mortality remains high in many developing countries in which the contribution of deaths among infants born very low birth weight (VLBW) may be considerable. This contribution has however not been quantified in most such countries. This paper explores a model that can be used in this respect.

Objective: To determine the contribution of very low birth weight infants towards the overall infants deaths in Kenya.

Design: Prospective cohort study.

Setting: Kenyatta National Hospital, Pumwani Maternity Hospital and Kilifi District Hospital.

Subjects: Very low birth weight infants followed up for a period of one year.

Results: The neonatal, post-neonatal and infant mortalities for the cohort were 442, 139 and 581/1000 respectively. These were thirteen, three and seven times higher than the national averages respectively. Of the national birth cohort of $1,300,000$ during that year, it was estimated that between $15,600(1.2 \%)$ and $24,700(1.9 \%)$ were born VLBW. Given this VLBW infant burden and extrapolating the infant mortality observed in this study to the general population, between $9,064(8.9 \%)$ and $14,351(14.2 \%)$ of the $101,400(78 / 1000)$ infants who die during infancy in the country are born VLBW.

Conclusion: The cohort reports very high infant mortality for VLBW infants when compared to the general population. Despite constituting less than $2 \%$ of the birth cohort, these infants contribute between $8.9 \%$ and $14.2 \%$ of all infant deaths.
\end{abstract}

\section{INTRODUCTION}

Almost $70 \%$ of the $120 / 1000$ under-five year deaths in Kenya occur during infancy (1). If the millennium development goal (MDG) of reducing the under five mortality in Kenya to $35 / 1000$ by the year 2015 is to be realised the infant mortality will have to be reduced drastically. Neonatal deaths are a major contributor to infant mortality in Africa with estimates of over $30 \%$ in most sub-Saharan countries including Kenya (2). Newborn survival strategies are therefore pivotal in the drive towards achieving the fourth MDG. Very low birth weight infants are expected to have higher neonatal mortality compared to their bigger usually moremature counterparts even in developed countries $(3,4)$. The factors that determine the impact of VLBW infants on the infant mortality rate (IMR) are their annual burden and specific mortality. In order to estimate the impact of VLBW babies on the national IMR, the authors employed this hospital based cohort to determine the VLBW specific IMR. The VLBW burden was then derived from a previous study based in a rural hospital (5) and unpublished data from the largest delivery unit in the country with over 20,000 births per year.

\section{MATERIALS AND METHODS}

Two hundred and sixty infants born weighing 1500grams or less at the Kenyatta National Hospital in the year 2002 were consecutively recruited. This was the entire hospital's birth cohort in that weight category during that year. Kenyatta National Hospital is a national referral and teaching hospital for the University of Nairobi. Thestudy was anon-randomised prospective cohort whose only inclusion criteria was birth weight below 1500grams. Non-residents of Nairobi were excluded due to follow-up logistics. The infants were recruited during the early newborn period with informed parental consent. All the infants completed the neonatal follow-up though three of them were not available for post-neonatal follow-up due to logistical reasons. The threewerehoweverincluded in the analysis and allocated into the worse outcome scenario. 
Information gathered and recorded at recruitment included;

(i) Gestational age confirmed by the clinical method described by Ballard (6).

(ii) Birth weight measured using the MisakiDigital Baby Scale with one-gram graduation and an upper limit of 20 kilograms.

(iii) Family identity information and addresses.

Follow-up commenced from recruitment till death or completion of the first year of life. The neonatal care was provided in accordance with the hospital's protocols and upon discharge family contact details were re-confirmed and follow-up numbers assigned. The site of follow-up was the hospital's routine developmental clinic for high-risk newborns. The principal investigator (FNW) reviewed all the patients at each clinic visit. In order to improve compliance, the infants were offered free clinical and developmental reviews as well as the routine iron and vitamin supplements. The reviews were set at three monthly intervals with freedom to visit the clinic on any other day as long as the clinic was in session.

Neonatal deaths were recorded as they occurred and reconciled with the hospital's death registry at the end of January 2003. There was no discrepancy between the two sets of records of neonatal deaths. Post-discharge mortality was obtained using the following methods;

(i) Parents / guardians self-reporting to the followup centre. The travel costs for this visit were reimbursed by the study.

(ii) Home visitor employed by the study to trace defaulters often found the reason for defaulting being death. The visitor recorded the date of death.

(iii) Telephone calls to a family member, relative or close friend when home visits did not succeed in tracing the child.

Attrition: Seven infants could not be accounted for at the end of the study due to default. An infant was considered a defaulter if they failed to attend the scheduled clinic and home visits and telephone tracing failed to find them.

Analysis: The denominator used during this analysis was 260 including the seven infants lost to follow-up and three neonatal survivors who were not available for the one year follow-up. The ten were included in the worst outcome category. The neonatal, post-neonatal and infant mortalities were then computed per 1000 live births. The 2003 Kenya Demographic and Health Survey (1) profiles were used as the national baselines for comparison. Two sources of data were used to estimate the national burden of VLBW infants.

(i) TheKilifiDistrict Hospital survey of 1998-2001 (5) which reported a burden of $1.2 \%$.

(ii) Un-published records at Pumwani Maternity Hospital, a big metropolitan hospital in Nairobi, which serves a wider spectrum of the average Kenyan mother with $1.9 \%$ burden.

These two are more representative of the broader Kenyan situation than Kenyatta National Hospital, a tertiary referral facility, with predominantly highrisk deliveries which was likely to exaggerate the VLBW burden.

Ethics: The study received approval by the hospital's ethics and standards committee while each parent/ guardian provided a signed consent after receiving a detailed explanation of the study and its value to the local fraternity.

\section{RESULTS}

Population characteristics: This was a birth cohort of 260 VLBW infants with 144 neonatal survivors. The baseline characteristics of the cohort at birth and those who survived the newborn period are presented in Table 1. The neonatal survivors were heavier $(\mathrm{P}<0.001)$ and more mature at birth $(\mathrm{P}<0.001)$ than the original cohort. Proportionately moreinfants with intrauterine growth retardation survived the newborn period compared to those born appropriate for gestation $(\mathrm{P}<0.001)$.

Table 1

Baseline characteristics

\begin{tabular}{llll}
\hline & Birth cohort & $\begin{array}{l}\text { Neonatal } \\
\text { survivors }\end{array}$ & Statistics \\
\hline Number & 260 & 143 & \\
Birth Weight, Mean \pm SD & $1240 \pm 106$ & $1380 \pm 96$ & ${ }^{*} \mathrm{P}<0.001$ \\
Gestation, Mean \pm SD & $30.3 \pm 2.8$ & $32.4 \pm 2.1$ & ${ }^{*} \mathrm{P}<0.001$ \\
Male: Female ratio & $1: 1.2$ & $2: 3$ & $\# \mathrm{P}=0.070$ \\
AGA: SGA ratio & $4: 1$ & $7: 3$ & $\# \mathrm{P}<0.001$ \\
\hline
\end{tabular}

*Analysis of variance $\# X^{2}$ distribution test 
Mortality profiles: These are summarised in Table 2. The group of 260 had $114(442 / 1000)$ neonatal and 151 (581/1000) infant deaths respectively. The post- neonatal mortality was $139 / 1000$. The neonatal and infant mortality were 13 and 7.5 times the national average.

Table 2

Mortality statistics

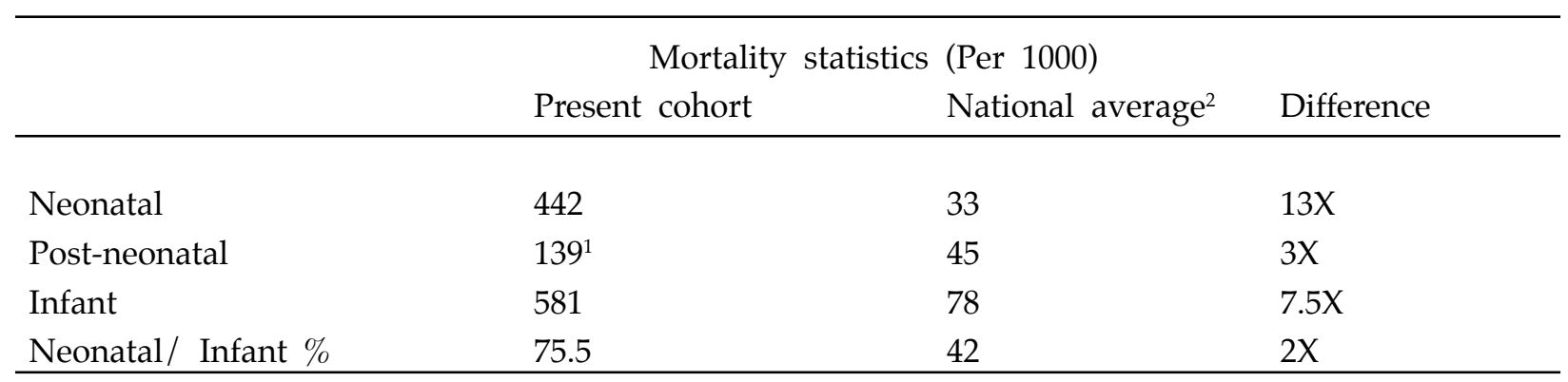

${ }^{1}$ The ten infants not accounted for included in the worse outcome group

Impact of VLBWinfants on overall infant: An estimate of the contribution of infants born weighing 1500grams and below is presented in Table 3. With the study's assumption that VLBW infants constituted 1.2-1.9\% of the total birth cohort, this group contributed 8.9$14.2 \%$ of the infant deaths. The VLBW neonatal deaths alone were projected to have contributed 16.1-25.4\% of all neonatal deaths in the national cohort.

Table 3

The impact of VLBW infants on overall infant mortality

\begin{tabular}{lllll}
\hline & $\begin{array}{l}\text { National } \\
\text { birth cohorts }\end{array}$ & $\begin{array}{l}\text { Neonatal } \\
\text { deaths }(\%)\end{array}$ & $\begin{array}{c}\text { Post- neonatal } \\
\text { deaths }(\%)\end{array}$ & $\begin{array}{l}\text { Infant } \\
\text { deaths (\%) }\end{array}$ \\
\hline $\begin{array}{l}\text { Total } \\
\text { VLBW Burden with 1.2\% }\end{array}$ & $1,300,000$ & 42,900 & 58,500 & 101,400 \\
$\begin{array}{l}\text { contribution } \\
\begin{array}{l}\text { VLBW Burden with 1.9\% } \\
\text { contribution }\end{array}\end{array}$ & 15,600 & $6,895(16.1)$ & $2,169(3.7)$ & $9,064(8.9)$ \\
\hline
\end{tabular}

The assumptions made in this module are, $1.2 \%$ (5) or $1.9 \%$ burden of VLBW infants in the national live-birth cohort and similar mortality among these babies the birth cohort as those described in the present study

\section{DISCUSSION}

This study attempts to quantify the contribution of VLBW infants to the overall infant mortality. The disproportionately higher neonatal, post neonatal and infant mortality seen here is consistent with previous reports from more advanced countries (4, 7-9). The advanced countries, however, not only have considerably lower infant mortalities (10) they also enjoy smaller proportionate representation of VLBW infants in their birth cohorts (11). The impact of VLBW infant deaths on infant mortality in poor countries is, therefore, bigger than that observed in the more economically advanced regions. This cohort found that VLBW infants while constituting only $1.2-1.9 \%$ of the national birth cohort accounted for $8.9-14.2 \%$ of the total infant deaths. The disproportionate contribution is explained by the considerably higher neonatal and infant mortality for the VLBW infants compared to the general population (Table 2). Though there is a global resurgence of concern on the burden of neonatal deaths in developing countries and its influence on the success of the fourth MDG (12), adequate and sustainable activities towards improved newborn survival are yet to take root in many of the poorer countries. The findings of this study suggest that the overall infant survival of VLBW infants should be a point of focus if the IMR is to be reduced in developing countries.

Some methodological issues confounded the deductions of this study. First, the national burden 
of VLBW infant births was based on information from two hospital based cohorts. These are likely to overestimate the burden since mothers with preterm or complicated labour are more likely to deliver in hospital than the normal ones. The kilifi study was in a rural district hospital (5) while Pumwani Maternity Hospital is a large metropolitan hospital with over 20,000 deliveries annually and patronised by the poorer urban populations of Nairobi. The second issue regards the extrapolation of neonatal and infant mortality statistics obtained in this closely supervised cohort of VLBW infants to the one expected for the general population. The supervised group is likely to do better than the general population which includes infants born at home or in smaller, less equipped facilities. From this point of view, the findings probably underestimate the true contribution of VLBW infants to IMR. Not withstanding these opposing limitations, the results suggest a notable contribution towards infant deaths by VLBW infants. Improving neonatal and infant survival towards achieving the fourth MDG in the country will require strategies aimed at reducing VLBW infants' neonatal and infant deaths.

\section{ACKNOWLEDGEMENTS}

To the University of Nairobi who provided the research grant for the work leading to the production of this paper and to Kenyatta National Hospital for allowing the facility to host the study.

\section{DECLARATION}

This study was part of FNW's doctoral thesis in the Department of Paediatrics and Child Health, College of Health Sciences, University of Nairobi.

\section{REFFERENCES}

1. Preliminary Report of the Kenya and demographic Health Survey 2003. Central Bureau of Statistics, Ministry of Planning. Website, www.cbs.go.ke 2003; pp27.

2. Information for Action; In: Opportunities for Africa's Newborns, Mills Litho, Cape Town. South Africa. 2006; pp 196.

3. Donald, D. M. Steven, L. B., Brian, M.C. and Kenneth, J.L. Birth weight in relation to morbidity and mortality among newborn infants. New Engl. J. Med. 1999; 340: 1234-1238.

4. McCormick, M.C. The contribution of low birth weight to infant mortality and childhood morbidity. New Engl. J. Med. 1985; 312: 82-90.

5. English, M.E., Muhoro, A., Aluda, M., Were, S., Ross, A. and Peshu, N. Outcome of delivery and cause-specific mortality and severe morbidity in early infancy: A Kenyan district hospital birth cohort. Am.J. Trop. Med. Hyg. 2003; 69: 228-232.

6. Ballard, J., Norak, K.C. and Driver, M. A simplified score for assessment of foetal maturity on newly born infants. J. Paediat. 1979; 95: 7689-7774.

7. Increasing infant mortality among very low birthweight infants Delaware, 1994-2000. MMWR. 2003; 52: 862-866.

8. Yu, V.Y.H., Watkins, A. and Bajuk, B. Neonatal and post neonatal mortality in very low birth weight infants. Archives Dis. Child. 1984; 59: 987-989.

9. Bowman, E. and Yu, V.Y.H. Continuing morbidity in extremely low birth weight infants. Early Human Development. 1988; 18: 165-172.

10. World Atlas-Ranking Infant Mortality Rates. www. geographyiq.com/ranking/rankinglnfantMortalityRateaa ll.htm.

11. Low birth weight incidence per country, UNICEF Global Data Base on LBW infants. www. childinfo. org/areas/birthweight.

12. United Nation's Millennium Development Goals http://www.unmilienniumproject.org/goals/goals02. htm\#goa 14. 